\title{
Cinema documental contemporâneo, técnica e sociedade: Implicações sociológicas e culturais
}

\author{
Gilmar Santana \\ Universidade Federal do Rio Grande do Norte, Brasil
}

\begin{abstract}
Frames of spots, cuts and movements, are important parts of the world cinematographic language. This cinematographic structure, reveals the intrinsic mixture of technical characteristics with the narrative wishes from the creative view of the filmmaker and the thematic issues which has been approached. In documentary cinema, these aspects come up because of cultural, political and ideological interests of the engaged authors in some social causes. The marketing purposes that currently dialogue with this kind of documentaries have created new forms of production and perception. From a comparative of two documentaries from different nationalities about artistic personalities such as "Amy", by Asif Kapadia (England, EUA, 2015) and "Chico, Brazilian artist" by Miguel Faria Jr (Brazil, 2015) deals with different phases of life, of Amy Winehouse and Chico Buarque de Hollanda, these documentaries aim to focus on sociological expressions that arise from this process in these both contemporary documentaries.
\end{abstract}

Keywords: Cinema, Culture, Documentary, Image, Society

\section{Introdução}

"Nunca amarre minhas asas. Deixe-me voar". (...) "Digo adeus só com palavras." (Amy Winehouse)

"As pessoas têm medo das mudanças. Eu tenho medo que as coisas nunca mudem." (...) "Eu canto a dor que eu não soube chorar."

(Chico Buarque de Hollanda)

A produção imagética documental, tem ganhado popularidade no cenário da cultura cinematográfica há algumas décadas. Apesar de já existir desde a origem do cinema, seu lugar logo ficou em segundo plano entre os gêneros, na medida em que ambiciosas produções de histórias "ficcionais" visando conquistar o grande público, se constituíram em poderosas fábricas de sonhos, sobretudo nos Estados Unidos da América (Schatz, 1991). Sem, no entanto, perder seu espaço de expressão, o cinema documentário desenvolveu-se criando diferentes formas narrativas e atraiu múltiplos adeptos (Da-rin, 2008).

Hoje, entre os fatores que contribuem para essa expansão, podemos apontar: a era digital que tornou cotidiana a produção e visualização de imagens em vários formatos; o conseqüente hábito do público de assistir histórias de diversos temas e linguagens, inclusive aquelas do vivido prosaico - muitas vezes contando suas próprias experiências - e o envolvimento da cultura de massa que encaixa incessantemente nas produções, seus vários apelos de consumo. Dentro desse vasto mundo de histórias, há tempos aquelas que falam de celebridades, em especial dos esportes e do show business, são alvo certeiro para despertar a curiosidade de parcela significativa de pessoas ávidas por saber particularidades de seus ídolos, razão pela qual, filmes biográficos revelam bilheteria garantida, logo, dividendos para a indústria cultural.

Tratando-se de documentários, o resultado tem se repetido, ainda que numa frequência menor. Assim, mais do que biografias de filmes sobre personalidades famosas, quando estas são diretamente protagonistas de suas trajetórias nos filmes, junto ao universo social que nelas orbita e em geral em função delas, vêse criar novas maneiras de percepção e atração de espectadores, fato que amplia segmentos, exige modos inovadores de narrar e portanto, conforma mercados específicos de consumidores apreciadores de um, dito nas palavras de Labaki e Mourão, "cinema do real" (2005). Cruzam-se nesse caso, projetos da indústria do entretenimento, com trabalhos de um gênero que sempre primou por ser o lugar de narrativas vinculadas a questões abordando diversidades temáticas políticas, denúncias sociais, busca pela revelação de problemáticas e culturas pouco conhecidas de uma maioria, e sobretudo, a um desejo de troca de experiências que permitissem maior aproximação das relações humanas e dos desafios que estas apresentam num contexto de rápidas mudanças em todos os âmbitos da sociedade global.

Se observarmos os dados compilados pelo Guia Knoforum - Festivais audiovisuais, pertencente à Associação Cultural Kinoforum, veremos em seus cadastros atualizados os principais festivais de cinema documentário no mundo. Somente no Brasil são mais de 230 eventos nacionais - entre festivais e mostras espalhados por todas as regiões do país e 215 internacionais. Atento a esse panorama, o viés mercadológico ocupa seu lugar buscando satisfazer públicos e ampliar este setor articulando temas e linguagens.

Diante desse contexto, a sociologia como ciência do presente, ocupada e participante de seu contínuo processo de transformações, encontra-se social e cientificamente num local favorável para a análise desse quadro: entre os acontecimentos contemporâneos, suas formas de manifestação e a reflexão destes. A sociologia da cultura e da imagem, em especial, contribuem com suas ferramentas analíticas para evidenciar o mosaico dessas sociabilidades e investigar nos filmes documentais novos processos culturais, políticos, artísticos e ideológicos apresentados. Em função desses aspectos, é possível ampliar o exercício desta ciência transformando o que antes era visto como recurso, agora utilizado como objeto de sua prática com a ampliação de análises em assuntos que fomentam a imagem propriamente dita. 
A reflexão a seguir, busca investigar essa problemática, por intermédio da análise comparativa dos filmes "Amy" dirigido por Asif Kapadia e "Chico, cidadão brasileiro" dirigido por Miguel Faria Jr., ambos produzidos no ano de 2015:

\section{Abordagens temáticas biográficas}

Falar de biografias, ainda que pareçam relatos fiéis descritivos sobre o biografado, na verdade significa falar de interpretações. Leituras de autores que selecionam aspectos sobre o que pretendem dizer e ressaltar de uma pessoa, para a partir disto, delinear sua trajetória. Por conseguinte, caberia melhor falar de "biografias" e não a "biografia" acerca de alguém, considerando a ocorrência de possíveis inúmeras versões.

Estes filmes teriam caráter cronologicamente literal ou apenas se proporiam a levantar alguns recortes da vida de determinadas pessoas? Fica difícil, nesse sentido, pensar apontamentos definitivos de qualquer personalidade pública retratada em imagens, especialmente estrelas musicais consagradas. É o caso dos protagonistas dos filmes para esta reflexão. Ambos já foram representados em mais de um documentário explorando diferentes nuances de suas vidas, ainda que o fio condutor geral envolvendo seus perfis pessoais tenha sido o mesmo.

O filme "Amy", do cineasta britânico descendente de indianos Asif Kapadia, tem produção dos EUA e Inglaterra. Também é sua a produção "Senna" (2010), documentário sobre o piloto brasileiro de fórmula 1 , Ayrton Senna, que a exemplo de "Amy", foi bastante premiado e bem recebido pelo público em geral. A realização brasileira "Chico, artista brasileiro", do diretor carioca Miguel Faria Jr, segue os mesmos passos de "Vinícius" (2005), um de seus trabalhos anteriores, que fala da vida do compositor, poeta, cantor e exdiplomata brasileiro, Vinícius de Moraes. Estas obras constarão oportunamente no final desse debate para efeito comparativo, no intuito de localizar a marca de estilo e abordagens temáticas de seus diretores. Nesse tópico, almeja-se refletir quais elementos da vida de determinadas pessoas que ao tocarem o gosto popular, despertam os interesses diversos, sobretudo comerciais, capazes de gerar histórias que passem a figurar como amplo registro social.

\section{a) Amy}

O filme desenvolve a trajetória de Amy Jade Winehouse, cantora e compositora britânica internacional de belíssima voz que além do jazz, blues, R\&B, soul, ska, incluía em seu repertório baladas românticas retrô, algo que lembra a nostalgia do rock dos anos 50 e 60, do século XX. Falecida aos 27 anos em julho de 2011, em sua casa no Camden Town, Londres, por conta da ingestão de bebidas alcoólicas em excesso, a estrela também teve problemas com o uso de drogas psicoativas, razão pela qual desde 2008, havia se afastado da indústria fonográfica.

Desde a infância a vida musical envolveu Amy por conta de sua família muito envolvida nessa área. Sua carreira "meteórica" com fama mundial de alta qualidade vocal e de intérprete, ganhou maior evidência quando suas questões pessoais também viraram mercadoria, moldadas pelas mídias sensacionalistas nacionais e internacionais.

O filme póstumo da estrela musical, bastante aclamado pela crítica e pelo público, traça esse panorama ao mesclar sua vida pessoal com a artística, incluindo vídeos caseiros com reportagens, shows com seus bastidores, entrega de prêmios e encontros com celebridades, além de ilustrar suas relações conflituosas com o ex-namorado Blake Fielver-Civil e seus afetos controversos com o pai.

Com linguagem de edição ágil, muitas vezes vizinha do vídeo-clipe, veículo inclusive de divulgação de seus trabalhos e já assimilado como discurso imagético, sobretudo para a juventude - seu público majoritário, percorre-se sua biografia em narrativa quase cronológica, deixando o público que assiste o filme a cada minuto na expectativa contraditória e lamentada da aproximação da morte anunciada da artista. A cada minuto de exibição, sabemos claramente que estamos indo ao encontro de seu fim trágico.

A articulação contínua entre cenas cotidianas de vida familiar, amigos, pronunciamentos da própria Amy, unindo seus momentos de glória e de crises garante um envolvimento que muitas vezes levam à ilusão de que estamos vendo uma história de personagem não real, como num roteiro de filme hollywoodiano. Ao mesmo tempo nega-se isso ao constatarmos a cada imagem, de que os registros misturando relatos de sua vida com suas turnês, glamour e notícias sensacionalistas fazem parte do que foi acompanhado pelas informações obtidas pela mídia no dia a dia da imprensa que convivemos rotineiramente. No entanto, não aparece como mote principal a ideia de uma memória da pessoa artista ou algo para o registro da música pop mundial. O que permanece presente é o choque conflituoso, a dificuldade em se administrar indivíduo e fama - a realização diluída em caos entre vida privada e pública.

\section{b) Chico, artista brasileiro}

Praticamente uma homenagem ao cantor, compositor e escritor, Chico Buarque de Hollanda, hoje com 75 anos de idade, esta obra cinematográfica de caráter histórico nacional, porque mistura seu lugar na vida política e artística na cultura brasileira, percorre sua trajetória pontuada por algumas de suas inúmeras canções, especialmente regravadas para o filme. Até os 12 primeiros minutos de projeção, vê-se uma genealogia de sua vida, ligando-o diretamente a todos os elementos afetivos, intelectuais e artísticos dos pais que influenciaram sua carreira e o prepararam para entrar na vida artística. O foco, portanto, não é a vida dele em si, mas sua trajetória como figura pública cultural.

As cenas seguintes revelam claramente a mudança de ambiente e sua inserção em um novo universo que aparece tanto em seu discurso como nas imagens de excessiva popularidade. Naquele momento já se visualiza o compositor consagrado que vemos hoje, ainda que as imagens sejam do passado. Nelas, 
há uma legitimação que integra temporalidades, reforçando seu lugar na vida cultural do país.

Há também um elemento sociológico importante que segue na trilha de Norbert Elias (1995) quando analisa a vida artística de Mozart: descarta-se a ideia de gênio, localizando-o como um artista resultado de um meio favorável ao desenvolvimento de suas potencialidades. Porém, diferente de Mozart que viveu uma criatividade pessoal cerceada, sem habilidade de negociação em uma sociedade que a todo tempo o controlava, estruturada histórica e socialmente apenas para os caprichos da corte, o Chico Buarque que se revela no filme é alguém que soube aprender e selecionar bem do seu meio social o que queria para sua vida pessoalintelectual, profissionalizando-se, ainda que sem muitas estratégias planejadas e calculadas.

Suas relações com as pessoas famosas, tanto no campo artístico como intelectual aparecem no próprio processo de sua formação pessoal e cultural obtida desde a infância. Quase todas eram membros do seu círculo familiar e por conseqüência, seguiram-se as outras que se agregaram a um universo artístico em amplo crescimento, na medida em que a vida do músico ganhava horizontes; fato que o próprio Chico afirma não ter dimensão dos acontecimentos que o levaram a isso - desses que se aproximam em muito ao que Weber chama de "hasard", ou acaso (Weber, 2202).

Em suas próprias palavras, num trecho do filme esta constatação apresenta-se reveladora:" - Mas eu ainda não achava que eu era um profissional. Prá mim aquilo né, ia passar. Passar rápido. Porque foi uma coisa meio que acidental". Claro, um acidente que por sua trajetória, já aparecia como algo previsível. Uma constatação que mostra posteriormente, seu olhar e valor modestos diante de sua experiência histórica com a fama e do lugar que adquiriu na cultura brasileira.

Com sutileza, as cenas tocam em algumas questões de sua vida pessoal como seu casamento e separação com a atriz Marieta Severo e a história do irmão alemão, resultado de uma relação extraconjugal de seu pai, o historiador e sociólogo Sérgio Buarque de Hollanda, quando de seu período de trabalho na Alemanha. Situação, entre outras que vinculadas a processos de sua vida que resultaram em produções artísticas, sejam elas músicas, peças teatrais ou livros.

Inevitavelmente, fala-se de sua participação artístico-política desenvolvida em quase toda sua trajetória, mas ali, novamente trata-se de desconstruir certos fatores que possam mitificá-lo, tanto na esfera pessoal como social. É o caso da imagem de pessoa tímida, que ele nega nos depoimentos e de suas intenções políticas nas obras, conforme afirma, terem sido oriundas muito mais da pressão de seu público, do que uma vontade pessoal no ato da criação.

\section{Diálogos possíveis}

Ambos os filmes celebram personalidades importantes do show business e significativas para a cultura contemporânea. Em imagens identificáveis tanto para fãs, como para não admiradores, os dois trabalhos apresentam marcas da notoriedade conquistada em suas caminhadas na música. As diferenças, porém, aparecerem de maneira evidente já pelos tempos de trajetória artística. Chico na época do filme com quase 72 anos e Amy falecendo com 27 anos, demonstram caminhos pessoais similares e distintos na esfera artística, em razão da própria estrutura da indústria fonográfica e do universo musical midiático que os cercaram desde o início da profissão.

Em particular ela, com muito menos tempo de carreira, pelo fato de estar inserida num mercado musical altamente competitivo e integrado a grandes outras indústrias no início dos anos 2000, quando gravou seu primeiro álbum, despertou interesse de empresários do ramo e rapidamente integrou-se no terreno de gravadoras internacionais ocupadas com lucros e qualidades artísticas "vendáveis". Ou seja, que além de qualidade musical, também revelem figuras marcantes, seja pela personalidade pessoal ou pela originalidade de algum talento artístico demonstrado. Amy possuía as duas características. Novamente a exemplo de Mozart, esteve envolvida com a música desde a infância. Porém, diferente daquele compositor, encontrou um quadro social completamente aberto para explorar suas potencialidades.

Chico, desponta no cenário musical por volta de 1965, quando grava seu primeiro disco compacto contendo as canções "Pedro pedreiro" e "Sonho de um carnaval". Mas será com 22 anos de idade em 1966, que ganhará notoriedade nacional, e depois internacional, quando conquista o primeiro lugar com a canção "A banda" no Festival de MPB da rede Record de televisão. Dali em diante, compete com suas composições nos anos 60 do século $\mathrm{XX}$, em vários festivais de música, eventos que premiavam e projetavam novos talentos musicais. Em meio a uma efervescência cultural e juvenil que ocorria no Brasil, já sob a égide da ditadura civil-militar implantada no país desde 1964, obteve fácil aceitação popular, sobretudo da juventude. Junto a esses fatores, ser jovem e sintonizado ativamente aos acontecimentos políticos que ocorriam tanto no país como no mundo, só veio somar elementos para o crescimento de sua fértil e promissora carreira artística.

Assim como outros companheiros músicos da época, Caetano Veloso, Gilberto Gil, Geraldo Vandré, Rita Lee, Roberto Carlos, entre outros, o carisma pessoal contava muito, considerando-se a incipiente indústria cultural de então. Em sua evolução, esta indústria buscou construir sobre eles personagens que refletissem personalidades viáveis para venda de imagens para o fortalecimento das intenções mercadológicas. Chico, por exemplo, deveria ser a imagem do bom moço de família.

Ações que ele mesmo e os outros músicos desconheciam, como atestam seus depoimentos no documentário "Uma noite em 67" (2010) de Ricardo Calil e Renato Terra, que fala sobre o terceiro festival de Música Popular Brasileira, ocorrido em outubro de 1967, na rede Record de televisão, em São Paulo.

Com talento de sobra, Chico Buarque, nunca precisou desse recurso de merchandising para difundir seus trabalhos. Fato análogo ao de Amy que, no entanto, por sua vida de dependência química e alcoolismo cada 
vez mais pública, serviu de interesse para a abertura de um outro mercado de atração popular por via de uma imprensa sensacionalista mundial que se utilizou de sua intimidade para construir uma personagem lucrativa para escândalos. Misturou-se assim, seu espaço público e privado numa imagem de pessoa perdida no meio da fama e incompreendida por todos.

Em várias situações do filme, isso fica bastante evidente. E o diretor busca assim, a todo momento, mostrar a pessoa repleta de sentimentos e afetos, a artista inspirada e sensível escondida atrás daquela "explosão" incontrolável e mal-educada construída pela grande mídia. Se reforça nesses termos a imagem da juventude rebelde sem causa, já construída por Hollywood com Marlon Brando, James Dean e na música, dentre outros com Janis Joplin. Tenta-se a todo instante reformatar os ídolos midiáticos atualizando-os e associando-os a uma linhagem de juventude moderna idealmente padronizada, elementos que o filme toca sem, no entanto, analisar criticamente su dimensão.

Sem afinidades políticas ou ideológicas que ela realmente não possuía, fica a imagem da rebeldia individual, da solidão e incompreensão social solapada pelos interesses mercadológicos de toda estrutura da indústria da música e seus parceiros, incluindose a participação do pai, retratado como ausente na infância de Amy e ocupado de maneira interessada com sua carreira na vida adulta, e do namorado de relação bastante conflituosa.

Nesse sentido, o perfil de Chico Buarque também destoa bastante da pop star. Ainda que de maneira moderada, ele nunca escondeu sua simpatia às esquerdas políticas e boa parte de sua obra sempre demonstrou sensibilidade aos grupos mais desfavorecidos da sociedade em geral. De canções românticas às de cunho social político, e mesmo em suas peças teatrais e livros, encontramos seu discurso dando voz aos oprimidos de vários segmentos e classes sociais.

De tal modo, revelam-se aqui perfis paradigmáticos não apenas personalidades marcantes, mas representações que bem aparadas nos formatos gerais de mercado de bens simbólicos, podem se tornar produtos atraentes. Mesmo nesses documentários, não se trata apenas de deixar um legado histórico sobre a relevância desses artistas, ainda que a preferência e simpatia dos diretores por eles sejam visíveis. Também eles como profissionais do ramo sabem que é necessário um investimento onde se contemple uma contrapartida que os garanta permanecer no campo cinematográfico.

Assim, já os critérios de selecionar pessoas que possuam algo mais que uma boa música, personalidades e histórias de vida possíveis de se transformarem em imagens atraentes para a identificação do espectador, são pressupostos essenciais para a elaboração de bons projetos culturais. Misturam-se nesse panorama os vários mecanismos do fazer cultural e cinematográfico. Revela-se, portanto, que a busca do espectador por filmes que emocionem, identifiquem, o projetem e o faça participar das imagens da vida das personagens (que de maneira associativa, são parte das nossas) é simplesmente uma pequena parte pesquisada de produtores que "generosamente" procuram trazer até seus públicos a realização de desejos de cumplicidade com celebridades nacionais ou mundiais.

Ocorre no universo da indústria cultural um complexo arranjo de interesses, que de certa forma sempre houve no mundo da arte, sobretudo com a formação de instituições e corporações (Williams, 2000). Agora, com a ampliação de públicos e com a especialização de funções, vários elementos técnicos, artísticos, culturais e sociais passaram a integrar as produções e alguns deles se projetaram nessas sociabilidades, adquirindo lugar de destaque, antes desvalorizados.

O reconhecimento do profissional garante distinções categóricas: patronatos, patrocínios, premiações, alcance de mercados, parcerias, manutenção e novidades entre produtores diante das tendências artísticas que redefinem suas posições e lugares no jogo dessas economias. Entre inúmeras contradições, geram-se novas obras, exercita-se a criatividade.

Numa estrutura empresarial a tensão constante entre $\mathrm{o}$ ato de criar e as necessidades de mercado, acaba por desenvolver, além de novas obras, novos públicos sobre os quais os meios de comunicação de massa permanecem sempre atentos. Nesse aspecto, o nicho dos documentários dialoga agora cada vez mais com todo esse arcabouço e não por acaso, também se preocupa com o que torna certos temas ou histórias de pessoas, objetos atraentes e vendáveis.

Como visto, é possível confluir para o mesmo plano perfis muito diferentes, mas ao mesmo tempo iguais nos quesitos do que se exige mercadologicamente e socialmente para a elaboração e difusão de obras artísticas. Sensíveis a todos estes fatores, cineastas buscam aos poucos também se legitimar diante de seu campo profissional dialogando com personalidades do universo cultural, também já legitimadas. Trazem a público seu estilo, suas reflexões sem, no entanto, perderem de vista seu lugar e projetos dentro desses espaços. Para isso, negociam simbólica e economicamente os diversos interesses presentes nesse tipo de mercado, buscando garantir suas identidades criativas. Assim como Chico Buarque e Amy Winehouse, também se estabeleceram na área artística diante da aprovação do público. Para isso, os filmes buscam jogar com os gostos, com as expectativas e com as novidades de informações que nos situam de modo problematizado sob novos olhares diante de personagens aclamadas culturalmente.

\section{Intenções mercadológicas}

Ainda que com alcances de público diferenciados, ambos trabalhos se conectam com a estrutura de produção e distribuição mundiais. "Amy" internacional e "Chico, artista brasileiro", nacional, são filmes de sucesso de bilheteria e conquista de prêmios dentro do gênero documentário. Com as produtoras: Universal Music, Film4, On The Corner Films, Playmaker Films, Krishwerkz Entertainmen e distribuição: Altitude Film 
Distribution, NOS Lusomundo Audiovisuais, "Amy" situa-se, pela própria estrutura de porte transnacional destas empresas, dentro de um mercado projetado para grandes investimentos. Além disso, não apenas este aparato logístico aparentemente técnico determina o sucesso de um produto, pensando-se aqui o cinema como mercadoria composta da fusão de elementos simbólicos e materiais. Paralelo aos indicativos de bilheteria, devem ser considerados como essenciais nesse tipo de mercado de bens simbólicos, o que podemos chamar de uma "fortuna crítica" que alimenta as obras provocando maior ou menor interesse do público consumidor.

Alternam-se nesse conjunto, críticos de arte e cinema, jornalistas, acadêmicos dedicados aos estudos de arte e cultura, revistas e jornais especializados e os inúmeros festivais, mostras e congressos espalhados pelo mundo afora que discutem, analisam, avaliam e premiam - muitas vezes também condenam - milhares de trabalhos todos os anos. Os dois filmes investigados aqui, passaram por esse crivo e também resultam dos próprios perfis de artistas consagrados em seus lugares, configurando-se, estes mesmos trabalhos como ferramentas de reforço da fortuna crítica já edificada em torno de seus protagonistas.

Amy Winehouse foi ganhadora de 30 prêmios musicais e 77 indicações o campo musical. Apenas para citar a dimensão de seu destaque, somente no Grammy Awards de 2008, nos Estados Unidos, recebeu 5 troféus. O filme seguiu em seu encalço já envolto na aura deixada pela estrela falecida em 2011. Situando-o entre os principais festivais de cinema mundiais, vemos que sua trajetória mirou suas cartadas com ousadia e segurança no investimento da produção. Em 2015, sem entrar no hall dos filmes competidores, estreou no $68^{\circ}$ Festival de Cannes com grande sucesso de público. Em 2016, ganhou como melhor documentário no BAFTA, considerado o Oscar britânico no Reino Unido. No mesmo ano, recebeu o prêmio de melhor de documentário do LAFTA Awards (Los Angeles Film Critics Association), organização de críticos de cinema que existe desde 1975, e logo depois o mesmo prêmio no Oscar, ambos nos Estados Unidos.

Segundo o site cineclick, este foi o documentário britânico de maior bilheteria na história do país. De acordo com o Deadline, o filme sobre a cantora e compositora britânica desde sua estréia até meados de agosto de 2015, já havia arrecadado US\$ 4,9 milhões (aproximadamente, $€ 4,4$ milhões). Na época, já ocupava o terceiro lugar entre os mais rentáveis no Reino Unido. Cabe aqui, considerar um fator cultural importante que marca este diferencial: sobretudo a Inglaterra, possui um grande histórico de relação com o cinema documental que remonta não somente as pesquisas cientificas e propostas educacionais, como também uma prática que se tornou crescente em bairros e cidades organizados em associações de moradores, operários e cineclubes temáticos direcionados a várias faixas etárias durante toda primeira metade do século $X X$. Ainda que aquela composição tenha se perdido, alguns hábitos cinematográficos do público e da indústria cultural sobreviveram resignificados.
"Chico, artista brasileiro" com produção da 1001 Filmes, Coprodução Globo Filmes \& Sony Pictures e distribuição da Columbia Pictures, também segue a mesma lógica de "Amy", haja vista a magnitude de inserção no mercado dessas empresas. Segundo o Anuário estatístico do cinema brasileiro, da Ancine, a película foi exibida em 52 salas de cinema no Brasil em seu lançamento no ano de 2015, com um público total de 97.697 e uma arrecadação na época de $\mathrm{R} \$ 1.516 .551,78$ (aproximadamente hoje: US\$ $381.435,52$ ou $€ 340.010,91$, em 2019). Comparando com os índices atingidos por "Amy", "Chico, artista brasileiro", parece estar num patamar irrisório. Porém, considerando-se a dimensão estimada para distribuição em salas de cinema pra o alcance de público para este gênero cinematográfico, o filme apresentou-se bem acima da média no Brasil. Ainda que no ranking dos 20 filmes brasileiros mais assistidos, apareça em $18^{\circ}$, seguido pelo $20^{\circ}$, o também documentário da cantora e compositora brasileira "Cassia Heller", com bilheteria de 75.133 espectadores, "Chico, artista brasileiro" é um documentário que disputou público com 18 filmes de gênero ficção, num país sem a tradição de expectadores para documentários, diferente da Inglaterra.

Sobre a trajetória do artista, assim como Amy Winehouse, Chico Buarque desde a infância esteve envolvido com a música. Sua mãe tocava piano, seu pai, já destacado intelectual no país, recebiam em casa várias personalidades do campo cultural. Dessa maneira, além da formação familiar ampliada com os amigos, seu universo se constituiu pela música erudita, por canções de Noel Rosa, Ataúlfo Alves e grande influência da bossa nova de João Gilberto. Em 1963, com 19 anos, participou do musical "Balanço do Orfeu" com a música "Tem mais Samba" e do show "Primeira Audição", no Colégio Rio Branco, com a canção "Marcha Para um Dia de Sol".

Em 1965, além do seu primeiro disco compacto gravado, musicou o poema "Morte e vida Severina" de João Cabral de Melo Neto e com as músicas ganhou o prêmio de crítica e público no IV Festival de Teatro Universitário de Nancy, na França. Porém sua projeção nacional e internacional só veio a ocorrer quando em 1966, venceu o Festival de Música Popular Brasileira com a canção "A Banda", cantada por Nara Leão, na rede Record de televisão. No ano de 1968, em parceria com Tom Jobim, venceu o Festival Internacional da Canção, com a música "Sabiá". No mesmo ano estreou na dramaturgia escrevendo a peça teatral "Roda viva", dirigida por José Celso Martinez, que por acabar se transformando numa crítica à ditadura, gerou inúmeros conflitos e ataques violentos que a levaram a ser censurada.

Por suas posições políticas críticas de denúncia social à realidade brasileira reveladas em seu trabalho, já com muitas músicas de sucesso, Chico recebeu ameaças do governo autoritário, fatos que o fizeram se exilar na Itália com sua esposa Marieta Severo. Em contrato com a gravadora Philips, produziu o disco "Apesar de você" que acabou censurado. Continuou realizando peças teatrais e diversas músicas em parcerias com outros artistas e intelectuais de renome 
na cultura brasileira. Em sua discografia constam 37 álbuns de estúdio, 9 álbuns ao vivo, 22 álbuns de compilação, 18 álbuns de vídeo e 1 de internet. No campo literário de seus 11 melhores livros, destacamse três que ganharam o prêmio Jabuti, o mais tradicional prêmio literário do Brasil, concedido pela Câmara Brasileira do Livro desde 1959: "Estorvo" (1882), "Budapeste" (2004) e "Leite derramado" (2010); Prêmio Casa das Américas em 2013, além do prêmio da APCA (Associação Paulista dos Críticos de Arte) em 2014, pelo livro "O irmão alemão". Chico Buarque também já foi indicado duas vezes (2008 e 2012) ao Grammy latino para o prêmio de melhor álbum e neste ano de 2019, pelo conjunto de sua obra, recebeu o Prêmio Camões, maior distinção em literatura de escrita portuguesa criado em 1988, pelos governos do Brasil e de Portugal.

É possível verificar nesse panorama, que as marcas da trajetória desses dois artistas levam consigo a forte presença de suas histórias pessoais de grande formação cultural e do encontro preciso entre reconhecimento de público e atenção de mercado. Mercado este, dedicado a explorar e divulgar não somente suas potencialidades criativas, com também seus perfis de imagem pública. Como é dito em seu filme, Emy era uma clássica garota judia do norte de Londres, bem tímida, mas com carisma. Chico, em razão de sua própria história envolvendo cultura e política, não é tímido, mas conseguiu construir uma vida de reservas que garantiu a proteção de sua esfera individual, sobretudo familiar. Processo inverso ao que ocorreu com Amy. Ambos possuem um grande senso de humor. Nos filmes isso fica muito evidente, mas o que se acentua é o quanto gostam do que fazem e como se dedicam aos seus afazeres criativos.

Nesse sentido, há um reforço ideológico que, por intermédio da difusão da infinidade de produtos realizados por estes artistas pela indústria cultural, os enquadra como referência naquele valor do trabalho produtivo como edificante para a construção do caráter cidadão burguês moderno que legitima este modelo de sociedade produtivista e consumista. Até o carisma e rebeldia que possuem, entra nessa fórmula da mercadoria pronta para venda. De maneira talvez não intencional, os próprios filmes demonstram isso ao apresentarem os vastos trabalhos realizados por eles.

"Amy", possui 34 canções, das quais 23 são cantadas por ela, 111 arquivos cedidos como cortesia de várias fontes, desde pessoais até empresas diversas que mostram sua vida pessoal, tournées, shows e relações variadas com a mídia. Os agradecimentos especiais revelam artistas músicos, jornalistas e fotógrafos famosos, seus parentes, amigos, que totalizam entre os principais, 85 pessoas. Dentre elas, várias personagens e celebridades que multiplicam sua fortuna crítica.

Comparando os mesmos dados, o que temos em "Chico, artista brasileiro", configura-se num total de 55 canções distribuídas entre 10 gravadas especialmente para o documentário, das quais apenas 3 são cantadas por Chico Buarque, 6 músicas incidentais tocadas no violão por Luis Claudio Ramos e 39 que fazem parte de arquivos e ilustram fotogramas. São 33 agradecimentos gerais e 6 especiais contendo grande parte de pessoas renomadas da cultura brasileira e algumas internacionais. As fotos pertencem a 18 fontes de acervos. Constam 19 arquivos, 5 trechos de filmes e somam-se 11 patrocínios entre setores privados e estatais.

Porém, em termos mercadológicos ao que parece, o diretor não buscou uma escalada tão ambiciosa como a do cineasta de "Amy". Os poucos dados disponíveis publicamente, atestam em 2015, apenas a participação do filme na $39^{a}$ Mostra Internacional de Cinema de São Paulo, sua exibição na abertura do Festival do Rio, com um prêmio de melhor fotografia de documentário pela $\mathrm{ABC}$ (Associação Brasileira de Cinematografia) e em 2016, sua exibição na $18^{a}$ mostra brasileira de cinema de Paris dentro do Festival Du cinéma brésilien de Paris e 4 premiações no Grande Prêmio de cinema Brasileiro da Academia Brasileira de Cinema.

Confrontados, os dados apresentam uma visão ampla que alterna as ações particulares das carreiras explicitamente bem-sucedidas e filmes que além de legitimarem seus protagonistas, também movimentaram todo o aparato da indústria cultural, considerando-se nesses termos a mobilização de profissionais de áreas diversas e a exposição de imagens que atualizam formas de percepção e atração pelas obras. Até os 30 primeiros minutos de exibição, "Amy" apresenta 11 canções, 7 shows e 32 vídeos. No mesmo tempo, "Chico, artista brasileiro" possui 9 canções, 4 shows e 19 vídeos. Enquanto o primeiro apresenta um tom narrativo crescente nesse sentido, mostrando o processo deveras alucinado em que Amy se envolveu, o segundo busca um equilíbrio que segue até o final acentuando os diálogos e as falas do próprio artista na longa entrevista de 20 horas que concedeu para o filme.

A busca pelo alcance de um determinado segmento de público em um, mais jovem, culturalmente mais geral, no outro um perfil mais maduro e de pressupostos culturais um tanto mais refinados, define a clareza profissional dos diretores sintonizados com seus ofícios. O que segura ambos é a linguagem fluída de formas documentais que alternam momentos de grande movimentação coletiva, com outros de grande intimidade. Essas perfomances reproduzem não apenas um estilo de abordagem que circunscreve narrativas acerca da área musical.

Elas consolidam aos poucos um novo recorte dentro do gênero documentário com ritmos e aproximações de seus personagens que ampliam o próprio consumo de suas produções já distribuídas pelo mercado de bens simbólicos. São reavivadas as vendas de CDs repaginadas com novas artes gráficas dos álbuns, lançam-se DVDs dos filmes posteriormente às suas exibições nos cinemas, apresentam-se novidades da vida dos artistas que despertam curiosidade para a busca de mais informações de produtos que satisfaçam os interesses diversos. Acoplados a isso, encontram-se as propagandas de múltiplos produtos em geral associados direta e indiretamente aos artistas misturadas em sites, anúncios televisivos 
e nas ruas, que impregnam olhares e motivam o consumo. O caso destes trabalhos é afetado por esses mecanismos acabando por reafirmar esses recursos já transformados em regra.

\section{Construção técnico-estética}

Há um mote geral segurando a narrativa dessas obras que passa intrinsecamente ligada à corporeidade dos artistas. Nos filmes de Asif Kapadia, tanto em "Amy" como em "Senna", fala-se de personagens já falecidas. Os discursos ancoram-se em extremos de vida e morte; respectivamente: sucesso e fatalidade. Nos dois, o espectador já sabe do destino de seus protagonistas e toda trama parece se transformar numa história ficcional, uma tensão constante, como num filme de suspense. A partir de uma reação social generalizada que se vê perplexa diante de pessoas jovens que no auge do prestígio profissional e econômico perdem a vida, faz-se uma reflexão simultânea sobre seu sentido e também acerca desse modelo de felicidade e realização ditados pelas ideologias preponderantes da sociedade moderna.

A ordenação editada fomenta suas trajetórias ascendentes de fama e, sobretudo em Ayrton Senna, sua personalidade obstinada. Nessa obra, acentuase sua precisão de projetos, sua discrição diante da riqueza conquistada, sua sobriedade de planos realçando como no automobilismo, a propriedade da técnica. Um perfil semelhante a um espírito calvinista, a todo instante esses elementos são associados à figura do piloto. A montagem do filme segue na mesma lógica equilibrando e dosando seu lado estratégico com uma vida disciplinada pessoal e profissionalmente.

"Amy", desenvolve um tom crescente de imagens que aceleram a vida da personagem, numa possível justificativa imagética de stress para seu fim trágico, como também foi o de Ayrton Senna. Entretanto, enquanto para ela leva-se o espectador a concordar que isso seria esperado naquele ritmo, com ele tudo ocorre de forma abrupta. Nas duas películas a conclusão sobre fama e valores existenciais convergem praticamente para o mesmo ponto. O ritmo que provoca essas emoções no público aparece como imprescindível para levar a essas reflexões.

De maneira contrária a estes, tanto em "Chico, artista brasileiro", como em "Vinícius", fala-se em outro tom. A experiência em torno da importância da vida marca suas imagens. No caso do primeiro, ele mesmo em franca vida criativa. O lugar da fama é substituído pela importância das relações coletivas, do encontro com amigos, das produções artísticas em parceria, do compromisso cultural e político com a cidadania. Dedica-se mais tempo nas cenas para os diálogos e discursos com ou sobre eles. As canções entram nas imagens como conseqüência dessas relações e não o ritmo linear da produção mercantil que visa conquistar metas. A linguagem fílmica construída busca imitar um cotidiano doméstico.

Assim, a construção da noção de tempo nesses dois diretores difere quanto às suas formas de aguçar sensibilidades nos espectadores. Os cortes são reveladores nesse aspecto. Enquanto nos filmes de Kapadia, caminha-se para um looping descontrolado da vida pessoal, já diluída na pública, dominada por empresários e seus lucros, evidenciado na montagem que alterna sequências entre relações pessoais e a vibração eloqüente das horas dessas personagens em suas atuações profissionais, em Faria Jr desembocamse em cenas do encontro de diálogo caseiro, da sala de estar, da varanda, das rodas de violão, bebidas entre amigos ou familiares. Fica evidente entre os diretores que almejam-se objetivos distintos. A quantidade de planos e formas enquadramento das obras aqui em foco deixa isso mais claro, conforme as tabelas a seguir:

\begin{tabular}{|l|c|c|}
\hline $\begin{array}{l}\text { Planos } \\
\text { 0:00 a 15:00 min }\end{array}$ & $\begin{array}{c}\text { Chico, artista } \\
\text { Brasileiro }\end{array}$ \\
\hline Gerais & 2 & 12 \\
\hline Conjunto & 11 & 12 \\
\hline Médios & 29 & 20 \\
\hline Closes & 29 & 7 \\
\hline Detalhe & 1 & - \\
\hline Planos & Amy & Chico, artista \\
\hline $15: 01$ a 30:0 min & Brasileiro \\
\hline Gerais & 19 & 7 \\
\hline Conjunto & 40 & 16 \\
\hline Médios & 50 & 18 \\
\hline Closes & 37 & 8 \\
\hline Detalhe & 14 & - \\
\hline
\end{tabular}

Pode-se visualizar acima, que entre os primeiros quinze minutos de cada filme e os outros 15 minutos posteriores, ocorre uma inversão de planos e enquadramentos. Enquanto em "Amy", ampliamse sensivelmente os planos gerais e algumas panorâmicas, em "Chico, artista brasileiro", se passa o contrário. Pelas imagens, pode-se notar que os dois avançam em suas vidas profissionais tornando-se mais visíveis publicamente.

Talvez, numa concepção visual linear se poderia naturalizar a ideia de maior abrangência social. Mas aqui reside o estilo narrativo de cada cineasta. A importância dada ao universo particular e depois pública, através do reconhecimento social que marca a vida de Amy Winehouse, faz Kapadia incluir esteticamente menos cenas familiares e ampliar sua projeção artística metaforicamente tornando seu domínio de território mais amplo utilizando os planos gerais e algumas panorâmicas.

Em "Chico, artista brasileiro", Faria Jr, parte do pressuposto de um Chico já consagrado, ainda desenvolvendo seu trabalho e de maneira poética, sua vida pessoal se mistura à vida coletiva do país. No decorrer do filme, vai convergindo para o fechamento, tanto do aumento de diálogos de um lado, como do 
fechamento político marcado pela censura do regime civil-militar da ditadura dos anos que se seguiram de 1964 a 1985.

Outro dado relevante a ser observado nas tabelas, são os planos médios, closes e de detalhe. Ali podese observar claramente a importância remetida à pessoalidade dos artistas e uma certa tentativa personalista, ao mesmo tempo em que mostra a necessidade dos diretores em trazer o espectador para mais perto da celebridade. Em "Amy" há um crescimento fabuloso destes planos, enquanto em "Chico, artista brasileiro", não aparecem sequer planos de detalhe. A proximidade fica por conta da narrativa em off do próprio Chico Buarque, que perpassa praticamente todo o filme e em cenas que misturam os fatos históricos com suas músicas, conjugação impossível de não emocionar até mesmo o espectador mais desavisado.

De qualquer forma, é nesse conjunto de planos e enquadramentos que se pode notar as intenções narrativas e estilísticas destes cineastas. Sobretudo, porque seus objetos mercadológicos e afinidades com estas personalidades são muito peculiares.

O diretor Kapadia constrói uma narrativa ágil, que carrega o espectador de informações visuais mantendo um mescla de tempo televisivo, como vídeo clipes e mensagens visuais da internet, deixando pouco espaço discursivo para a reflexão. A quantidade crescente dos cortes e planos não poderia ser diferente. É o que inclusive, já se apresenta no mercado de forma já assimilada para ser digerido. Sua relação com a estrela pop não é pessoal. Ela atende a objetivos possíveis de grande retorno do investimento, fato que realmente aconteceu.

Do mesmo modo, no processo inverso, a importância delegada à fala, ao debate e à reflexão é clara no trabalho de Faria Jr. Já em "Vinícius", os mesmos elementos apareciam. Ele próprio afirma em entrevistas que decidiu repetir a fórmula. Sua proximidade com Chico também é ímpar. Sustentam uma amizade há décadas, experiência que por ela mesma já resultaria outra forma no tecer da obra.

Por óbvio que pareça, fica aqui evidente que nenhuma linguagem, sobretudo estética, está isenta de múltiplos interesses e suas formas ideológicas se constituem na totalidade concreta, material e simbólica das obras acabadas ainda que aparentem simplesmente um recurso técnico. Mesmo o processo de negociação mercadológica e o lugar do autor, já determinam a formação desse quadro.

\section{Considerações finais}

$\mathrm{Na}$ trilha das reflexões de Raymond Williams, não há como se furtar a entender as realizações cinematográficas como 0 conjunto das forças produtivas que fundem o trabalho pessoal de ambos os artistas com todas as empresas que arrastam consigo, os próprios filmes. O fazer simbólico, material, cultural, político e econômico de uma obra artística, se apresenta dialeticamente como o conjunto de fatores determinantes e determinados das obras sociais contemporâneas.
Ainda que há tempos essa condição se realize, do que cabe ao nosso contexto atual é compreender que tudo o que se produz hoje passa de alguma forma por esses mecanismos. Só é possível pensar a produção cultural de massa hoje considerando-se esse conjunto de fatores conectados. Por sua vez, convém observar que em sua aparente harmonia, encontram-se os mais inúmeros conflitos de interesse em vários níveis sociais. Além disso, essa forma de profusão informativa, muda não apenas nossa percepção sobre as pessoas, artistas e maneiras de criar. Modifica também nossa concepção sobre cultura e, portanto, de como entender e apreciar o ato de analisar e perceber imagens, como algo não somente visto fisicamente pelo olhar.

Cada vez mais se torna imprescindivel observar como estas imagens dialogam com nossos desejos e projetos cotidianos. Com as perspectivas de sociedade sendo construídas e qual delas contribuímos pessoal e socialmente para alimentar.

Todo o trabalho na sociedade moderna supõe uma solidariedade, no sentido durkheimeano e marxiano do termo. Ocorre que não de maneira simplesmente pragmática ou utilitarista, o documentário supõe e prescinde de uma rede de solidariedade pessoal, direta de relações. Arquivos, fotos, vídeos, cartas, jornais, são fragmentos materiais essenciais de memória que constituem qualitativamente a narrativa, compondo sua veracidade, seu conteúdo profundo de sentimentos. Facilitado pela amizade do diretor Miguel Faria Jr. com Chico Buarque, filme que provavelmente não existiria sem esse fator afetivo, o documentário "Chico, artista brasileiro", transforma-se numa obra íntima, de memória não somente deles, mas da história cultural e política do Brasil. É um trabalho sobre a importância da memória.

Esta preocupação memorial não existe em "Amy", ao que parece, fica muito mais a impressão da descrição da fama e consolidação da artista como parte da ordem de um universo pop mundial que com essas obras garante muito mais à indústria fonográfica do que à memória da artista, uma elaboração cosmológica de celebridade que justifica todo o sistema cultural global vigente. De qualquer forma, se construiu uma memória, ainda que com viés mercadológico.

Sabe-se enfim, que qualquer obra artística é passível de reprodução, ressignificação e invenção de outras, dentro dela mesma. O documentário referenda a regra. Possui várias vertentes e esta bastante comercial, tem expandido horizontes. No entanto, como pôde ser visto nessa reflexão, num mesmo ano, com os mesmos aparatos técnicos, industriais, comunicacionais e mercantis, se revelaram obras de qualidade, porém bastante distintas. Assim, continua em lugar central o ser humano, a construção e a importância de suas memórias, mesmo que múltiplas e controversas. O que vale é a dimensão criativa engajada no que a humanidade em sua reflexão, pode fazer de melhor. O documentário tem o compromisso de fazer, nesse sentido, cumprir sua parte. Ajudar o público espectador a sonhar, rever suas vidas ao se projetar e imaginar um mundo diferente, se possível, melhor. 


\section{Referências bibliográficas}

Adorno, Theodor W., Horkheimer, Max. 1973. Temas

Básicos da Sociologia, São Paulo: Cultrix/Edusp.

Alea, Tomaz Gutierrez. 2009. Dialéctica Del espectador. Medellín: ediciones EICTV.

Benjamin, Walter. 1994. Walter Benjamin, obras ecolhidas: magia, técnica, arte e política, São Paulo: Brasiliense.

Bernardet, Jean-Claude. 1985. Cineastas e imagens do povo. São Paulo: Brasiliense.

Da-rin, Silvio. Espelho partido - tradição e transformação do documentário. 4.ed. 2008. Rio de Janeiro: Azougue.

Elias, Norbert. Mozart - sociologia de um gênio. 1995. Rio de Janeiro: Jorge Zahar editor.

Escorel, Eduardo; Goifman, Kiko; et alli. outubro/ dezembro de 2003. Cinemais 36 - objetivo/subjetivo: especial documentário.

Gauthier, Guy. O documentário - um outro cinema. 2011. Campinas, São Paulo: Papirus.

Kellner, Douglas. A cultura da mídia. 2001. Bauru, São Paulo: Edusc.

Loach, Ken. Desafiar El relato de los poderosos. 1.ed. 2014. Ciudad autónoma de Buenos Aires: Paidós.

Mclane, Betsy A. A new history of documentary film. 2.ed. 2012. New York: Bloomsbury.

Meleiro, Alessandra (org.). Cinema no mundo indústria, política e Mercado. V. 2 e v. 5. 2007. São Paulo: Escrituras editora.

Cinema e mercado - indústria cinematográfica e audiovisual brasileira. v. 3. 2010. São Paulo: Escrituras editora.

Mourão, Maria Dora e Labaki, Amir (orgs). 2005. O cinema do real. São Paulo: CosacNaify.

Morin, Edgard. 1970. O cinema ou o homem imaginário, Lisboa: Moraes.

Schatz, Thomas. 1991. O gênio do sistema. São 'Paulo: Companhia das letras.

Xavier, I. (org.). 1983. A experiência do cinema, Rio de Janeiro: Graal/Embrafilme.

Weber, Max. 2002. "Ciência como vocação" in Ensaios de sociologia. 5. ed., Rio de Janeiro: LTC.

Williams, Raymond. 2000. Cultura. 2. ed. Rio de Janeiro: Paz e terra.

\section{Sites}

http://www.kinoforum.org.br/guia/festival https://oca.ancine.gov.br/sites/default/files/repositorio/ pdf/anuario_2015.pdf

https://www.cineclick.com.br/noticias/amy-e-odocumentario-britanico-de-maior-bilheteria-de-todos-ostempos

https://ebiografia.com/chico_buarque/

\section{Filmografia}

Amy (Amy), 2015, EUA; Dir.: Asif Kapadia

Chico, artista brasileiro (Chico, artista brasileiro), 2015 Brasil; Dir.: Miguel Faria Jr.

Senna (Senna), 2010, EUA, França, Reino Unido; Dir.: Asif Kapadia

Uma noite em 67 (Uma noite em 67), 2010, Brasil, Dir: Ricardo Calil e Renato Terra

Vinícius (Vinícius), 2005, Brasil; Espanha, Dir.: Miguel Faria Jr. 